\title{
Localisation of renin-angiotensin system (RAS) components in breast
}

\author{
M Tahmasebi', S Barker', JR Puddefoot ${ }^{*}$, and GP Vinson' \\ 'School of Biological Sciences, Queen Mary, University of London, Mile End Road, London EI 4NS, UK
}

\begin{abstract}
Angiotensin II has mitogenic and angiogenic effects and its receptors are widespread, particularly in epithelial tissue. Tissue renin angiotensin systems (tRASs) may be a local source of angiotensin II that has specific paracrine functions. To investigate the presence of a tRAS in normal human breast and tumours. Immunocytochemistry, and quantitative RT-PCR was used to establish: (i) the presence and localisation of RAS components, (ii) the possibility of their involvement in cancer. (I) mRNA coding for angiotensinogen, prorenin, angiotensin converting enzyme (ACE), and both ATI and AT2 receptors was demonstrated in normal and diseased breast tissues. (2) (pro)renin was identified in epithelial cells in both normal and diseased tissue, but in invasive carcinoma, its distribution was mostly confined to fibroblasts or could not be detected at all. (3) Angiotensin converting enzyme was shown in epithelial cells in both normal and malignant tissue. The results are consistent with the hypothesis that a tRAS is present in the breast, and is disrupted in invasive cancer.

British Journal of Cancer (2006) 95, 67-74. doi: I0.1038/sj.bjc.66032I3 www.bjcancer.com
\end{abstract}

Published online 6 June 2006

(c) 2006 Cancer Research UK

Keywords: breast cancer; (pro)renin; angiotensin converting enzyme (ACE); ATI, AT2 receptors; angiotensinogen

The renin angiotensin system (RAS) has received most attention in relation to its functions in the circulation, in which the generation of the active hormone, angiotensin II (Ang II), is associated with the regulation of aldosterone secretion, salt and water metabolism and blood pressure (Mulrow, 1999; Kaschina and Unger, 2003). In recent years, attention has also focused on the evidence for widespread local tRASs (Mulrow and Franco-Saenz, 1996; Vinson et al, 1997; Tahmasebi et al, 1999; Nielsen et al, 2000; Li et al, 2004).

Angiotensin types 1 and 2 (AT1 and AT2) receptors are present in many different tissue types, and in particular, the AT1 receptor is abundant in secretory epithelial tissue (Vinson et al, 1995, 1997; Marsigliante et al, 1996). As Ang II and tRASs may have an important role in tissue growth and modelling these observations lead to the possibility that tRASs are involved in cancer.

While Ang II has been used in cancer to enable better accessibility of chemotherapeutic drugs to the tumour (Noguchi et al, 1988), Ang II blockers and ACE inhibitors have nevertheless been shown to reduce tumour size, angiogenesis and metastasis (Fujita et al, 2002; Uemura et al, 2005), although the suggestion that long-term use of angiotensin converting enzyme (ACE) inhibitors in patients may limit the development of cancer (Lever et al, 1998) has been questioned (Li et al, 2003; Ronquist et al, 2004).

Tahmasebi et al (1998) showed the transcription of (pro)renin in fibroblasts and myoepithelial cells in normal and abnormal

\footnotetext{
*Correspondence: JR Puddefoot;

E-mail: J.R.Puddefoot@qmul.ac.uk

Received 10 March 2006; revised 9 May 2006; accepted II May 2006; published online 6 June 2006
}

breast tissue, suggesting the existence of a tRAS within the breast. The generation of Ang II within the breast would support the hypothesis that Ang II could directly or indirectly contribute to breast cancer progression (Inwang et al, 1997; Tahmasebi et al, 1998; De Paepe et al, 2001).

Using immunocytochemistry, and real time RT-PCR, the present study addresses the possibility that a tRAS exists in normal and cancerous breast tissue,

\section{MATERIALS AND METHODS}

\section{Quantitative RT - PCR}

Quantitative RT - PCR (QRT - PCR) was carried out using Taqman fluorogenic probe and primers specific for angiotensinogen, prorenin, ACE and the angiotensin receptors (AT1 and AT2) (Applied Biosystems, Warrington, UK). Total RNA from normal human liver, kidney and lung (BD Biosciences, Clontech, Oxford, UK) were used to set up standard curves for each gene as appropriate (five-fold serial dilutions ranging from 0.4 to $250 \mathrm{ng}$ of total RNA per reaction, in triplicate). Values for normal breast and breast tumour (infiltrating ductal carcinoma) (BD Biosciences, Clontech) were obtained as anoograns RNA equivalents of the reference gene in each case derived from the corresponding standard curve. Reverse transcription and PCR amplification were performed in an MX3000P real time PCR system (Stratagene) using SuperScript ${ }^{\mathrm{TM}}$ III one-step qRT - PCR reagent (Invitrogen, Paisley, UK) under the reaction conditions described in Table 1. Nucleasefree water was used in place of RNA template as a nontemplate control (NTC). 
Table I Thermal cycling parameters for qRT-PCR

QRTPCR parameters

\begin{tabular}{lccc}
\hline & & \multicolumn{2}{c}{ PCR amplification cycles } \\
\cline { 2 - 4 } \multicolumn{2}{c}{ Initial steps } & Melt & Anneal/extend \\
\hline $30 \mathrm{~min}$ & $10 \mathrm{~min}$ & $15 \mathrm{~s}$ & $30 \mathrm{~s}$ \\
$50^{\circ} \mathrm{C}$ & $95^{\circ} \mathrm{C}$ & $95^{\circ} \mathrm{C}$ & $60^{\circ} \mathrm{C}$ \\
\hline
\end{tabular}

\section{Immunocytochemistry}

Tissue collection

Formalin-fixed, paraffin wax-embedded and frozen human tissue sections: Human breast tissue samples were provided with appropriate informed consent from patients undergoing surgery. Ethical approval was granted from the Local Ethical Committee. Patients undergoing breast surgery (mean age 58 years), included normal breast tissue and benign (23 patients), premalignant and malignant breast lesions (77 patients). Paraffin wax-embedded and frozen tissues were generously provided by $\mathrm{Dr} C$ Brown (Department of Morbid Anatomy, Royal Hospitals Trust, London) and Ms S Jones (Department of pathology, St Bartholomew's Hospital, London) respectively.

Antibodies: The monoclonal anti-renin mouse IgG antibody 2D12 was a gift from Professor Pierre Corvol (Collège de France, Paris) and the polyclonal anti-ACE mouse IgG, from Chemicon International Inc (Hampshire,UK) Anti-vimentin (mouse IgM), anti-cytokeratin (mouse IgG) and anti-actin mouse (IgG) antibodies (Sigma, Poole, Dorset, UK) were used to discriminate between fibroblasts, epithelial cells and myoepithelium, respectively. Other reagents were from Sigma unless stated otherwise.

Avidin-biotin immunodetection-frozen tissue sections: Frozen tissue sections $(4-8 \mu \mathrm{m})$ were fixed with acetone on poly-L-lysinecoated slides and fixed in cold acetone, washed in three changes of Tris-buffered saline (TBS, pH 7.6, $50 \mathrm{mmol}$ Tris/l, $150 \mathrm{mmol} \mathrm{NaCl} /$ 1, $2 \mathrm{mmol} \mathrm{MgCl}_{2} / \mathrm{l} \mathrm{pH} \mathrm{7.4)} \mathrm{and} \mathrm{incubated} \mathrm{for} \mathrm{5-10} \mathrm{min} \mathrm{in} \mathrm{hydrogen}$ peroxide $(0.1-1 \%)$ in TBS. Finally, sections were washed in TBS twice for $5 \mathrm{~min}$ at room temperature. Nonspecific antibody binding was blocked with $1 \%(\mathrm{w} / \mathrm{v})$ normal rabbit blocking reagents (Boehringer Mannheim, Germany) and the sections were incubated with their respective primary antibodies for either $90 \mathrm{~min}$ at room temperature or overnight at $4{ }^{\circ} \mathrm{C}$ in a humidification chamber. Negative control samples were incubated with TBS buffer alone. Unbound antibody was removed by washing $3 \times$ for $3 \mathrm{~min}$ in TBS. Specific binding was detected by incubating the sections with secondary biotin-conjugated antibody, rabbit anti-mouse IgG, (1:300-1:400; DAKO, Cambridgeshire, UK) for $30 \mathrm{~min}$ and amplified using an avidin/streptavidin, biotinylated enzyme complex (ABC) system (DAKO) according to the manufacturers instructions followed by visualisation using diaminobenzidine hydrochloride (DAB, 3,3'-diaminobenzidine). Sections were counter-stained using Harris haematoxylin (VWR, Poole, UK) destained in acid alcohol $(10 \mathrm{ml} 1 \% \mathrm{HCl}$ in $990 \mathrm{ml}$ of $70 \%$ industrial methylated spirit (IMS; VWR). Sections were dehydrated by washing in $95 \%$ alcohol, $100 \%$ alcohol $(2 \times 1 \mathrm{~min})$, and finally xylene, $(2 \times 3 \mathrm{~min})$ prior to mounting in Depax mounting medium (VWR).

Avidin-biotin immunodetection-paraffin wax embedded sections: Waxed embedded tissue sections were washed in xylene, $3 \times 5 \mathrm{~min}$ and rinsed in 100, 90 and $80 \%$ alcohol $(2 \times 2$ min washes each). To block endogenous peroxidase activity, sections were incubated in $3 \%$ hydrogen peroxide $(\mathrm{v} / \mathrm{v})$, diluted in methanol for
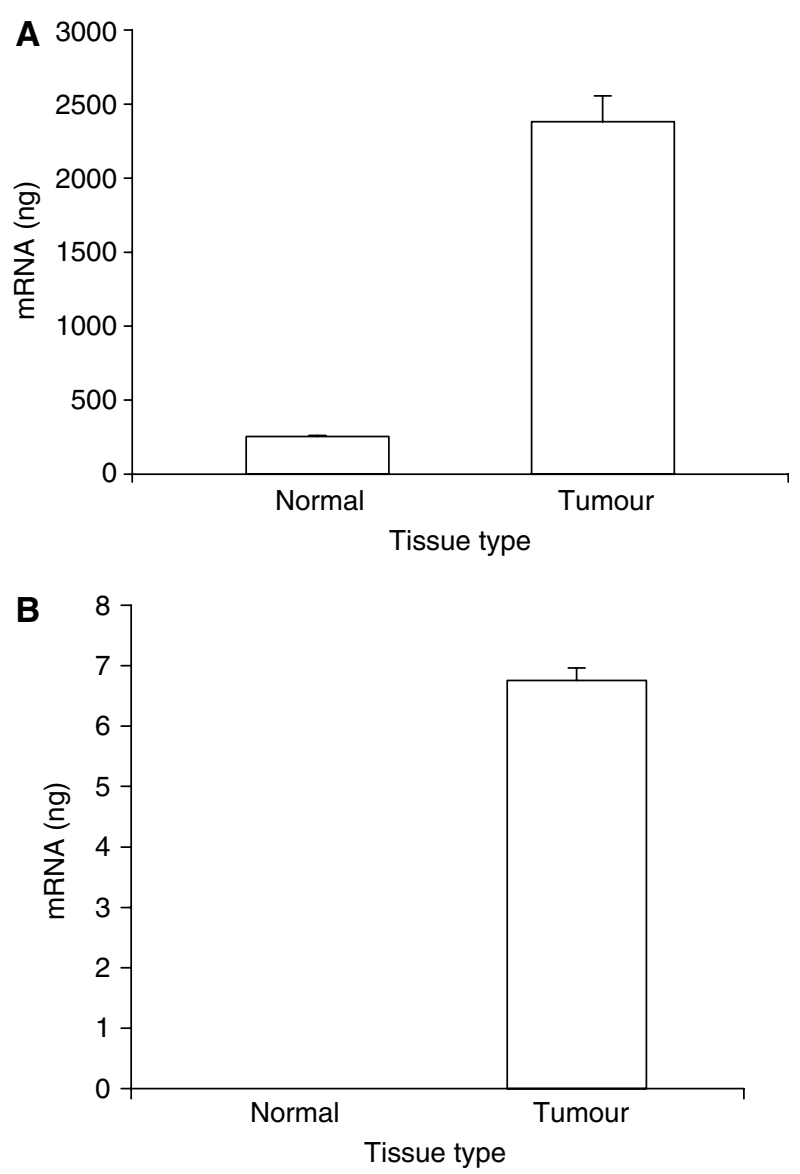

Figure I Quantitative result for ATI (A) and AT2 (B) receptor mRNA transcription using real time reverse transcriptase-polymerase chain reaction ( $\mathrm{RRT}-\mathrm{PCR}$ ) in normal breast tissue and infiltrating ductal carcinoma. Samples used contained $75 \mathrm{ng}$ total RNA from normal breast and tumour tissue.

$15 \mathrm{~min}$ at room temparature. Sections were washed in distilled water for $10 \mathrm{~min}$ and microwaved $(700 \mathrm{~W})$ for $16 \mathrm{~min}$ in $10 \mathrm{mmoll}^{-1}$ citrate buffer. Immunostaining was carried out at as previously described.

Breast cancer cell lines fixed on to the poly-L-lysine slides: MCF-7 and T47-D breast cancer cell lines were purchased from European Collection of Animal Cell Cultures (ECACC; Salisbury, UK) and routinely cultured (Puddefoot et al, 2002). Cells were harvested and seeded on to poly-L-lysine coated slides, then incubated at $37^{\circ}$ under $5 \% \mathrm{CO}_{2}$ for $24 \mathrm{~h}$ in a serum-free medium.

Slides were washed briefly with TBS $(\mathrm{pH} 7.6)(2 \times 1 \mathrm{~min})$, then fixed in cold acetone for $5 \mathrm{~min}$ and airdried prior to immunocytochemistry as above.

\section{RESULTS}

\section{QRT - PCR}

AT1 and AT2 receptors Values for AT1 and AT2 receptor mRNA expression were obtained by reference to a standard curve generated using normal human kidney total RNA. Normal breast tissue gave a value for AT1 receptor mRNA comparable to that found in human kidney or lung, however, the breast tumour sample showed a much higher abundance of AT1 receptor mRNA, 10-fold higher than found in normal breast tissue (Figure 1A). 
AT2 mRNA was barely detectable in normal breast tissue, but it was clearly present in breast tumour, albeit at lower levels than in either kidney or lung (Figure 1B). Nontemplate control tubes gave no detectable amplification.

RAS components Values for angiotensinogen (AGT), prorenin and ACE mRNA expression were obtained by reference to standards curves generated using normal human liver, kidney and lung total RNA, respectively. AGT mRNA was detected at relatively low, although significant levels in both normal breast and in breast tumour samples. Nontemplate control tubes gave no detectable amplification. There was no significant difference between the levels of AGT mRNA found in normal and breast tumour tissue (Figure 2A).

Prorenin mRNA was also present in both normal breast and breast tumour samples and although values were relatively low, significantly higher levels were detected in normal compared to breast tumour tissue (Figure 2A).

ACE mRNA was also lower in tumour tissue compared with normal tissue (Figure 2B). In both cases, nontemplate control tubes gave no detectable amplification.

Immunocytochemistry Cellular identification was confirmed by reference to slides immunostained for cytokeratin (epithelial cells), actin (myoepithelial cells), and vimentin (fibroblasts) (results not shown).

(pro)renin In normal tissue sections, immunoreactive (pro)renin was shown to be distributed almost exclusively in myoepithelial cells (Figure 3A), and connective tissue while epithelial cells showed virtually no staining. In contrast, in fibroadenoma tissue, (pro)renin was now found to be localised in epithelial cells (Figure 3C), as well as in myoepithelial cells, and stromal fibroblasts and connective tissue. Control sections in the absence of primary antibody (Figure $3 \mathrm{~B}$ and $\mathrm{D})$ showed no immunostaining.

In malignant tumours, most of the (pro)renin staining was seen in myoepithelial cells with, some patchy staining in epithelial cells, and also in fibroblasts.
In ductal carcinoma in situ, positive (pro)renin staining was observed in the myoepithelial cells and fibroblasts as a disrupted band surrounding the ducts. The staining varied from a uniform

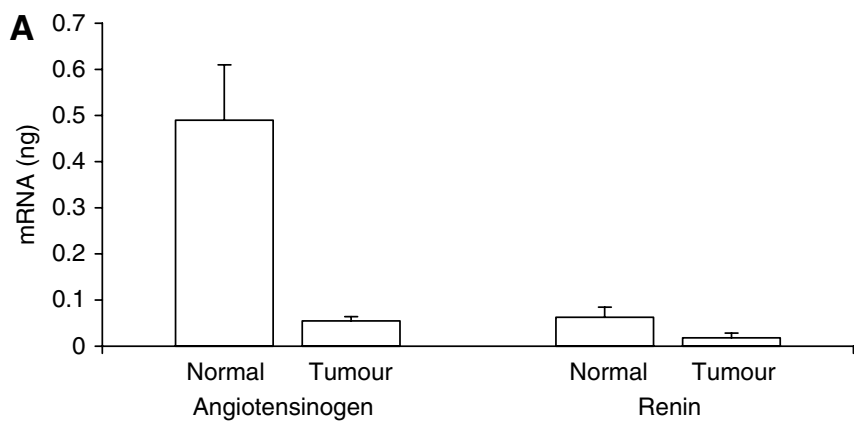

B

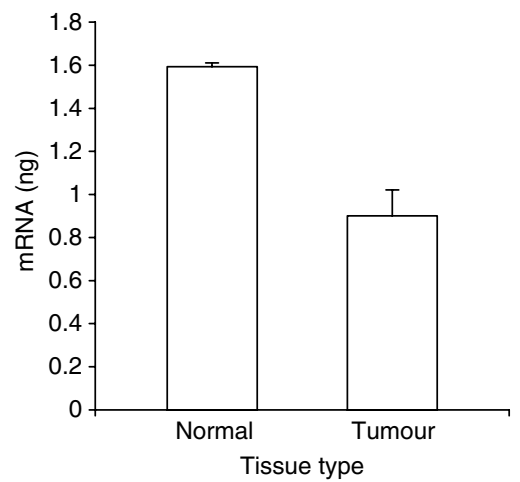

Figure 2 Quantitative result for angiotensinogen, prorenin and ACE mRNA transcription using real time reverse transcriptase-polymerase chain reaction ( $q R T-P C R$ ) in normal breast tissue and infiltrating ductal carcinoma. Samples used contained $250 \mathrm{ng}$ total RNA from normal breast and tumour tissue for angiotensinogen and prorenin $(\mathbf{A})$, and $75 \mathrm{ng}$ total RNA from normal breast and tumour tissue for ACE (B).
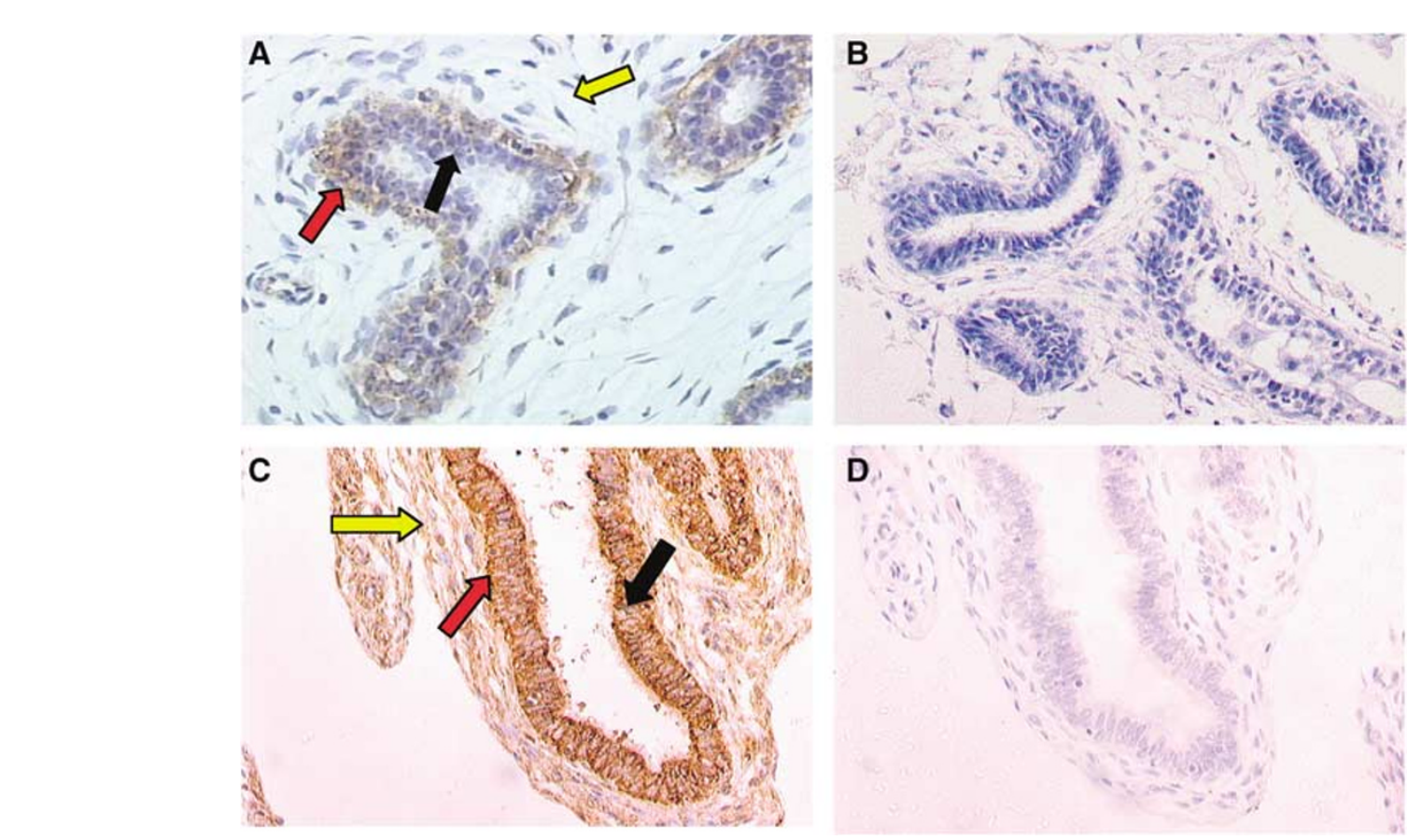

Figure 3 (Pro)renin was localised in sections of formalin-fixed, paraffin-embedded normal breast tissue. (A) Immunoperoxidase staining shows the antigen (pro)renin was present in myoepithelial cells (red arrow). Staining was absent from epithelial cells (black arrow) and connective tissues (yellow arrow). In fibroadenoma (C), immunoperoxidase staining shows the (pro)renin was present in epithelial cells, myoepithelial cells, and connective tissues. Control sections, omitting primary antibody, showed no immunostaining (B \& D). Magnification $\times 200$. 
and usually strong staining of most cells at intensity equivalent to that seen in normal tissues to rather patchy, less positive staining (Figure 4A). Nevertheless, (pro)renin expression was present in all cases. Epithelial cells showed no immunoreactivity. The staining reaction was abolished in the absence of primary antibody (Figure 4B). In infiltrating ductal carcinoma grade II, (pro)renin staining was absent from the majority of fibroblasts whereas some epithelial cells showed positive staining (Figure 4C). When present, myoepithelial cells showed positive staining. Control sections, omitting primary antibody showed no immunostaining (Figure 4D).

In grade III intraductal carcinoma, the cancer cells show little (pro)renin staining, and instead, the fibroblasts frequently show the greatest abundance of the antigen. The pattern of
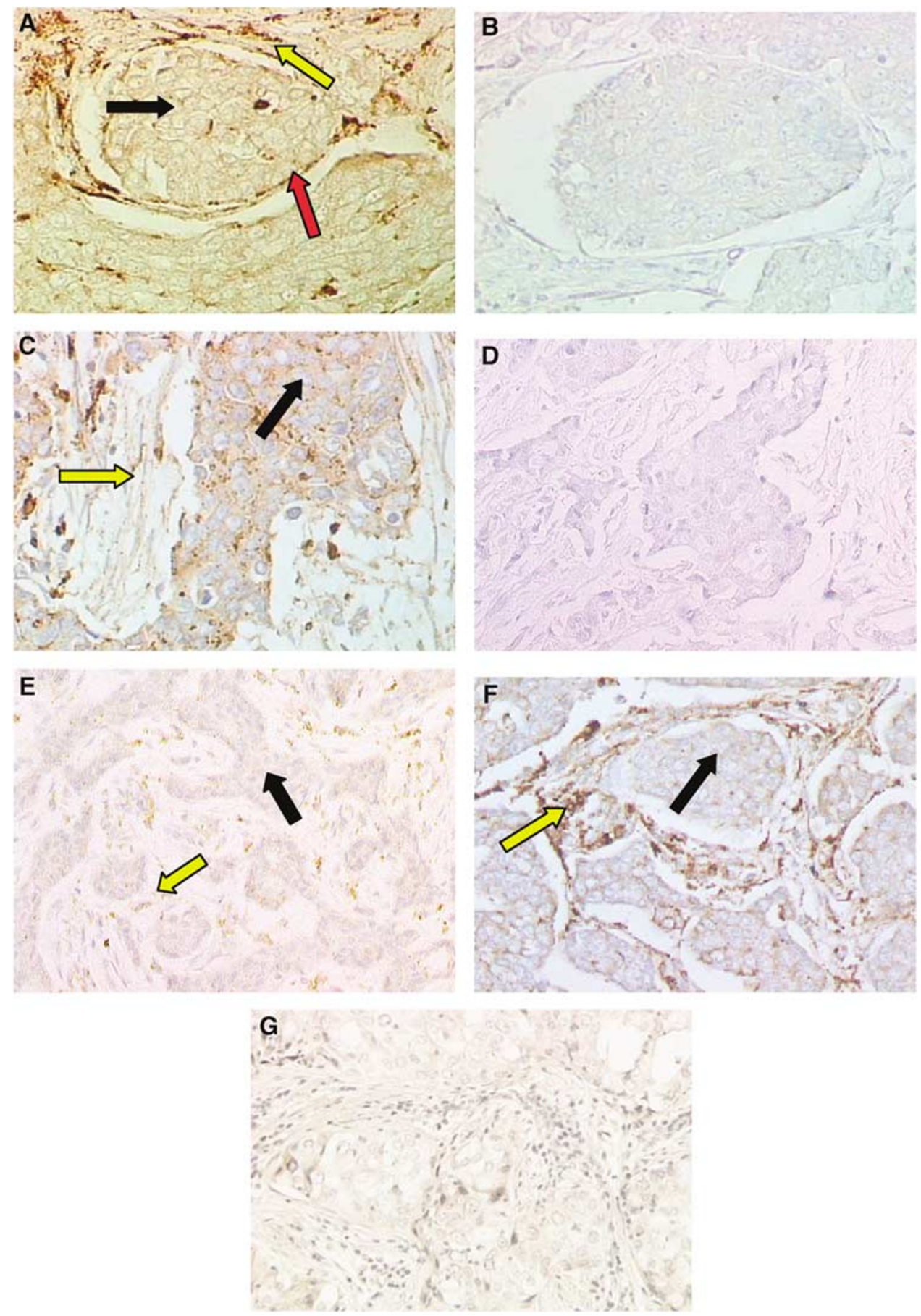

Figure 4 (Pro)renin was localised in sections of formalin-fixed, paraffin-embedded ductal carcinoma in situ. (A) Immunoperoxidase staining shows the antigen was present in myoepithelial cells (red arrow) and fibroblasts (yellow arrow). Staining was absent from epithelial (cancer) cells (black arrow). In infiltrating ductal carcinoma grade II (C) (pro)renin was present in epithelial cells (black arrow). Staining was absent from majority of the fibroblasts (yellow arrow). In infiltrating ductal carcinoma grade III (E), the antigen was present in fibroblasts (yellow arrow). Staining was absent from epithelial cells (black arrow). In lobular carcinoma in situ (F) the antigen was present in fibroblasts (yellow arrow) with a very weak staining in epithelial cells (black arrow). Control sections $(\mathbf{B}),(\mathbf{D})$, and $(\mathbf{G})$, omitting primary antibody, showed no staining. Magnification $\times 200$. 
staining was variable, and ranged within individual sections from uniform and strong, to a more patchy distribution with weak or moderate staining which did not reach the intensity seen in normal tissues. However, in some cases of poorly differentiated invasive carcinoma, epithelial cells showed some immunoreactivity with only a weak, patchy staining in fibroblasts (Figure 4E).

In lobular carcinoma in situ, positive staining for (pro)renin was observed in myoepithelial cells and connective tissues surrounding the lobules (Figure $4 \mathrm{~F}$ ). A very weak stain was shown in the cytoplasm of the epithelial cells. The negative controls in the absence of primary antibody showed no staining (Figure 4G).

Both MCF-7 (Figure 5A) and T47-D (Figure 5B) cell lines showed strong prorenin expression. Control sections for MCF-7 cell line, gave no staining in the absence of primary antibody (Figure 5C).
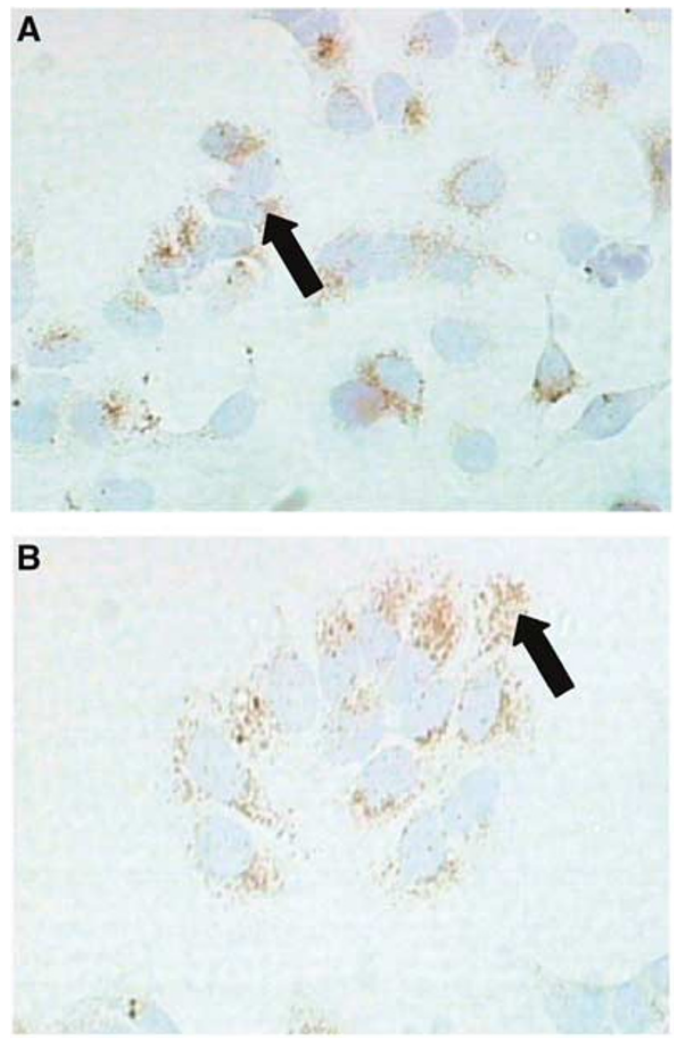

C

Figure 5 Immunoperoxidase staining of methanol-fixed MCF-7 (A) and T47-D (B) breast cancer cells. (Pro)renin was present in both (black arrow). There was no staining in the absence of primary antibody, shown here for MCF-7 cells $(\mathbf{C})$. Magnification $\times 200$.
ACE These studies were carried out on frozen sections because the primary antibody used was suitable for frozen sections, but not for paraffin-embedded sections.

The results show that ACE was present in epithelial cells of normal breast and virtually all the epithelial cells were positively stained (Figure 6A). In all cases fibroblasts were negative. The negative control shows no staining in the absence of the primary antibody (Figure 6B).

In fibroadenoma too, epithelial cells, stained positively for ACE (Figure 6C).

The connective tissues surrounding the ducts were completely negative. The negative control shows no staining in the absence of the primary antibody (Figure 6D).

In invasive ductal carcinoma grade III, ACE was expressed in the epithelial cells but apparently less uniformly strong than in normal tissue (Figure $6 \mathrm{E}$ and $\mathrm{F}$ ). The staining intensity ranged from strong in benign cells to moderate in poorly differentiated cancer cells. The negative control shows no staining in the absence of the primary antibody (Figure 6G). In all cases the connective tissue showed no immunostaining.

\section{DISCUSSION}

It is increasingly clear that the the functions of the RAS extend beyond its roles in sodium and potassium homeostasis and the regulation of blood pressure and many studies have shown that it has a wider significance. For example, Ang II also has trophic and apoptotic activities in various cell types (Bedecs et al, 1997; Dinh et al, 2001; Kaschina and Unger, 2003; Li et al, 2005). Furthermore, immunolocalisation of the AT1 receptor also strongly suggests that Ang II has a widespread role in maintenance of epithelial structure and function (Vinson et al, 1995, 1997). Such functions may include the regulation of water and electrolyte transport (Vinson et al, 1995; Quan and Baum, 1996) as well as mitosis and tissue differentiation (Bedecs et al, 1997; Li et al, 2005).

As Ang II and tRASs may have an important role in epithelial tissue growth and modeling, it is possible that they may be involved in cancer.

There is clear evidence for the presence of Ang II receptors in different types of cancer. (Marsigliante et al, 1996; De Paepe et al, 2001; Deshayes and Nahmias, 2005; Suganuma et al, 2005). In breast tissue, both AT1 and AT2 receptors are present, and the AT1 is located in both lobular and ductal epithelial cells in normal and benign breast tissues (Inwang et al, 1997), and increased AT1 receptor mRNA transcription has been shown in cancer as compared with normal cells (Greco et al, 2002a), although receptor expression may decrease in invasive carcinoma, compared with hyperplasia or ductal carcinoma in situ (De Paepe et al, 2001). In addition, AII has been shown to have an influence on breast cancer cell metastasis throught its control of integrin expression (Puddefoot et al, 2006). From this evidence, it is a clear possibility that Ang II may be involved in the maintenance of normal breast and epithelial tissue structure, and in vitro studies have shown stimulation of proliferation in primary breast tissue cultures via the AT1 receptor, together with the importance of the PKC pathway involved (Greco et al, 2002b; Muscella et al, 2002).

There is evidence too for the existence of tRASs in cancer. The expression of angiotensinogen, (pro)renin, ACE, and AT1 and AT2 receptors has been demonstrated in glioblastoma tumours and glioblastoma cells in culture, in which renin has a direct role in proliferation and/or survival (Juillerat-Jeanneret et al, 2004). In an earlier study from this laboratory, (pro)renin gene transcription was demonstrated in normal and abnormal breast tissue using in situ hybridisation (Tahmasebi et al, 1998). (Pro)renin transcription was found in nearly all samples, but there were differences between normal and abnormal tissue. In normal breast ducts, transcription was seen in myoepithelial cells and in 

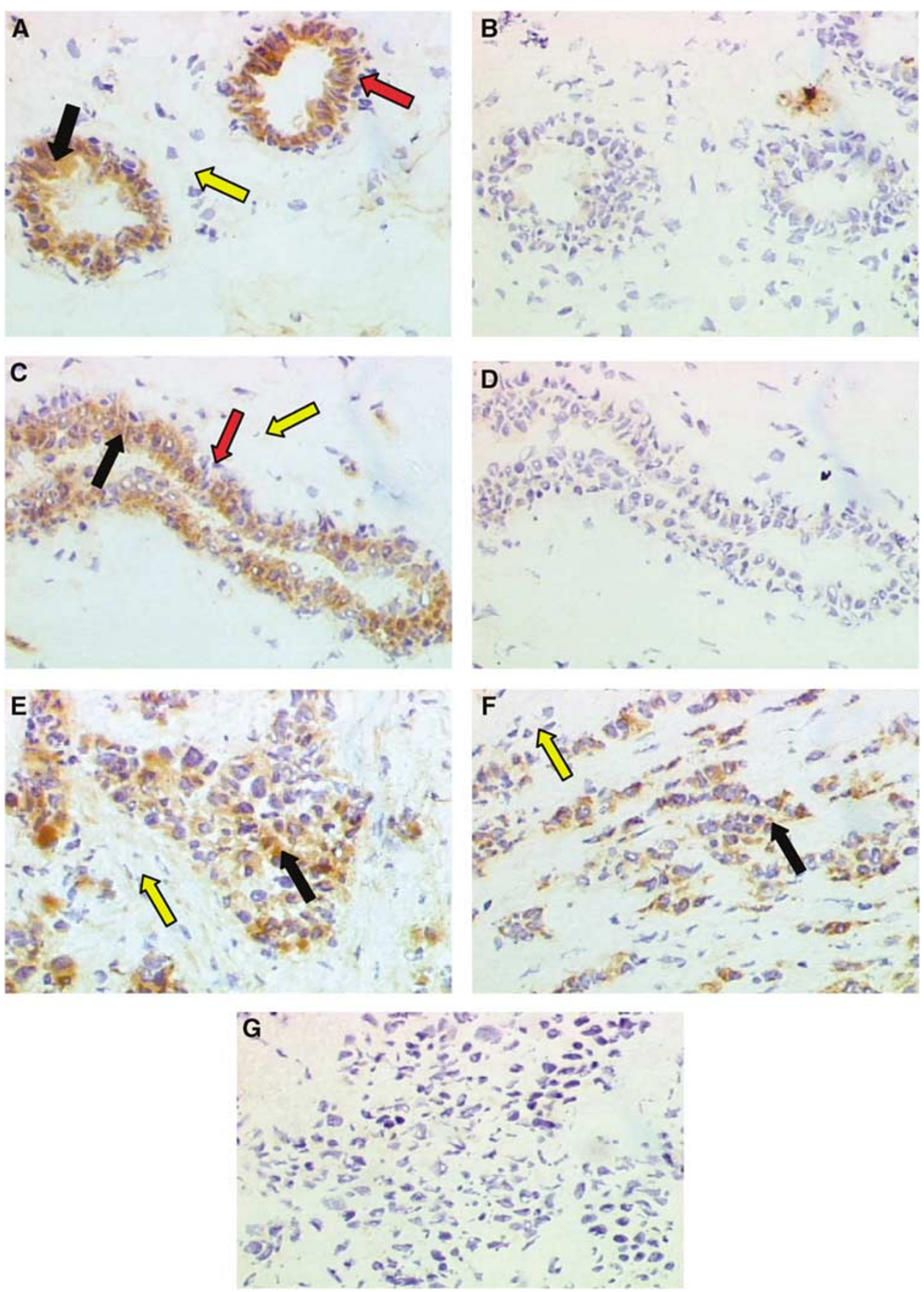

Figure 6 ACE was invariably localised in epithelial cells in frozen sections of all tissue examined, illustrated here for normal breast tissue (A) fibroadenoma (C) infiltrating ductal carcinoma grade III (E, F). Staining was absent from myoepithelial cells (red arrows) and connective tissues (yellow arrows). Control sections, omitting primary antibody, showed no immunostaining $(\mathbf{B}, \mathbf{D}, \mathbf{G})$. Magnification $\times 200$.

fibroblasts, but none was found in the secretory epithelium. In cancer, overall renin transcription was seemingly reduced with the loss of myoepithelial cells, and it also became more sporadic in fibroblasts.

To extend these studies, the present work was designed first to confirm the presence of AT1 and AT2 receptor mRNA, together with mRNA coding for components of the RAS. Quantitative RT-PCR analysis revealed the transcription of AT1 and AT2 receptor mRNA in both normal and diseased human breast tissues though AT1 mRNA was much more abundant in carcinoma than in normal tissue (Figure 1A and B), thus supporting the growing body of evidence discussed previously that increased AT1 receptor expression may contribute to mammary carcinoma (Greco et al, 2002a). Angiotensinogen mRNA was present in very low amounts compared with the liver and prorenin mRNA was present although lower than in the kidney (Figure 2A), unsurprisingly, since liver and kidney are usually considered to be the major sources of these components (Mulrow, 1999; Kaschina and Unger, 2003). However, confirming the previously reported in situ hybridisation data (Tahmasebi et al, 1998), there was significantly less (pro)renin mRNA in carcinoma than in normal tissue. Finally, the quantification of ACE mRNA showed that expression was present in carcinoma, although again in lower amounts than in normal tissue (Figure 2B). 
This demonstrates that RAS components may be produced in the breast, and leads to the question of their localisation.

In the present study, immunocytochemistry revealed that, in most samples of normal breast tissue, (pro)renin was in present in abundance in myoepithelial cells but, unlike its mRNA, it was absent from connective tissues surrounding the ducts (Figure $3 \mathrm{~A}$ ). This was also true in ductal and in lobular carcinoma in situ (Figure 4A and F). Different staining patterns were seen in fibroadenoma (Figure 3C), and in infiltrating ductal carcinoma (Figure 4C) in which the antigen was weakly and sporadically present in epithelial cells, but also more strikingly in fibroblasts as well. Abundance of (pro)renin also varied according to the stage of malignancy, suggesting that its expression varied inversely with tumour grading. Thus, (pro)renin staining was still present in fibroblasts, although at relatively low intensity (Figure 4E).

Together with previous data on the distribution of mRNA, which in normal tissue was detected mostly in fibroblasts and myoepithelium, the data suggest that (pro)renin, is formed in the fibroblasts (and myoepithelium) and is transported from the connective tissue site of synthesis, perhaps to myoepithelium (although the myoepithelium is also a source), and possibly even to the epithelium, though this is has only been faintly visible in some of the abnormal samples (Figure 4C). In cancer, although, (pro)renin mRNA and protein are both found in fibroblasts. This suggests that the intimate association between fibroblasts, myoepithelium and epithelium are essential for any such transfer to occur. Together with the progressive loss overall of both (pro)renin mRNA and protein, such physical disruption suggests that the system for local Ang II generation is greatly impaired in cancer.

The localisation of ACE is especially important to the concept of a local RAS supplying purely local requirements for Ang II. The immunohistochemical results presented here shows that ACE is largely distributed in the epithelial cells in human benign and malignant breast tissues (Figure 6A, C, E and F). This distribution matches that of the AT1 receptor, but is different from that of (pro)renin. It suggests that Ang II in breast tissue is not necessarily derived from the circulation and may originate from a local source. Most importantly, it suggests that Ang II is produced directly in the epithelium, the site at which it acts. Clearly it may be formed from Ang I provided by renin activity in the myoepithelium. This reveals a tightly organised RAS that is geared to the production of hormone in the breast duct epithelium alone.

It is the apparently close coupling of (pro)renin and ACE expression with the epithelial site of Ang II action that is so compelling about the data presented here. As Ang II has numerous functions in epithelial and other tissues, including the regulation of mitosis and tissue differentiation, the observation that (pro)renin transcription apparently fails in invasive carcinoma, crucially suggests that here Ang II is not available to maintain these functions. This has profound implications for our understanding of cancer. We conclude that the local tRAS may be important for the regulation of epithelial function in the breast. Such regulation is lost as the renin producing fibroblasts and myoepithelium are physically separated from the bulk of the proliferating cells. The characteristic invasiveness of malignant cells may reflect this loss of RAS control.

\section{CONCLUSION}

It is known that Ang II has a role in tissue structure and cell proliferation, and its proliferative actions have been shown in breast cancer cells. It is also known that the ductal epithelium is abundantly supplied with AT1 and receptor, and, from the present work, also with ACE. From previous and from the present work, it is also now known that the epithelium is surrounded by fibroblasts and myoepithelial tissue that transcribe and express (pro)renin, and angiotensinogen mRNA is also present. These findings show the possibility of a tRAS in the breast that is tightly coupled to the site of action of the active hormone, Ang II. This system is disrupted in cancer, leading to the possibility that failure of the RAS, and Ang II production may contribute to the functional phenotype of cancer cells.

A better understanding of the progression-specific alterations in tRAS components in breast cancer could therefore be helpful in the development of targeted therapies.

\section{REFERENCES}

Bedecs K, Elbaz N, Sutren M, Masson M, Susini C, Strosberg AD, Nahmias C (1997) Angiotensin II type 2 receptors mediate inhibition of mitogenactivated protein kinase cascade and functional activation of SHP-1 tyrosine phosphatase. Biochem J 325: $449-454$

De Paepe B, Verstraeten VL, De Potter CR, Vakaet LA, Bullock GR (2001) Growth stimulatory angiotensin II type 1 receptor is unregulated in breast hyperplasia and in situ carcinoma but not in invasive carcinoma. Histochem Cell Biol 116: 247-254

Deshayes F, Nahmias C (2005) Angiotensin receptors: A new role in cancer? Trends Endocrinol Metab 16: 293-299

Dinh DT, Frauman AG, Johnston CI, Fabiani ME (2001) Angiotensin receptors: Distribution, signalling and function. Clin Sci (London) 100: $481-492$

Fujita M, Hayashi I, Yamashina S, Itoman M, Majima M (2002) Blockade of angiotensin AT1A receptor signaling reduces tumour growth, angiogenesis, and metastasis. Biochem Biophys Res Commun 294: 441-447

Greco S, Elia MG, Muscella A, Storelli C, Marsigliante S (2002a) AT1 angiotensin II receptor mediates intracellular calcium mobilization in normal and cancerous breast cells in primary culture. Cell Calcium 32: $1-10$

Greco S, Muscella A, Elia MG, Salvatore P, Storelli C, Marsigliante S (2002b) Activation of angiotensin II type I receptor promotes protein kinase C translocation and cell proliferation in human cultured breast epithelial cells. J Endocrinol 174: 205-214

Inwang ER, Puddefoot JR, Brown CL, Goode AW, Marsigliante S, Ho MM, Payne JG, Vinson GP (1997) Angiotensin II type I recptor expression in human breast tissue. Br J Cancer 75: 1279-1283
Juillerat-Jeanneret L, Celerier J, Bernasconi CC, Nguyen G, Wostl W, Maerki HP, Janzer R-C, Corvol P, Gasc J-M (2004) Renin and angiotensinogen expression and functions in growth and apoptosis of human glioblastoma. Br J Cancer 90: 1059-1068

Kaschina E, Unger T (2003) Angiotensin AT1/AT2 receptors: Regulation, signalling and function. Blood Pressure 12: 70-88

Lever AF, Hole DJ, Gillis CR, McCallum IR, Mclinne GT, Mackinnon PL, Meredith PA, Murray LS, Reid JL, Robertson JWK (1998) Do inhibitors of angiotensin-I-converting enzyme protect against risk of cancer. Lancet 352: $179-184$

Li CI, Malone KE, Weiss NS, Boudreau DM, Cushing-Haugen KL, Daling JR (2003) Relation between use of anti hypertensive medications and risk of breast carcinoma among women ages 65-79 years. Cancer 98: 1504-1513

Li J, Kaschina E, Elkhrbash K, Timm M, Sommerfeld M, Unger T (2005) Divergent roles of angiotensin AT1 and AT2 receptors in myocardial ischemia-induced apoptosis and inflammation. Hypertension 46: 906-907

Li YH, Jiao LH, Liu RH, Chen XL, Wang H, Wang WH (2004) Localization of angiotensin II in pig ovary and its effects on oocyte maturation in vitro. Theriogenology 61: $447-459$

Marsigliante S, Resta L, Muscella A, Vinson GP, Marzullo A, Storelli C (1996) AT1 angiotensin II receptor subtype in the human larynx and squamous laryngeal carcinoma. Cancer Lett 110: 19-27

Mulrow PJ (1999) Angiotensin II and aldosterone regulation. Regul Pept 80: $27-32$

Mulrow PJ, Franco-Saenz R (1996) The adrenal renin-angiotensin system- a local hormonal regulator of aldosterone production. J Hypertension 14: $173-176$ 
Muscella A, Greco S, Elia MG, Storelli C, Marsigliante S (2002) Angiotensin II stimulation of $\mathrm{Na}+/ \mathrm{K}+\mathrm{ATPase}$ activity and cell growth by calciumindependent pathway in MCF-7 breast cancer cells. J Endocrinol 173: $315-323$

Nielsen AH, Schauser KH, Poulsen K (2000) Current topic: The uteroplacental renin-angiotensin system. Placenta 21: 468-477

Noguchi S, Miyauchi K, Nishizawa Y, Sasaki Y, Imaoka S, Iwanaga T, Koyama H, Terasawa T (1988) Augmentation of anticancer effect with angiotensin II in intraarterial infusion chemotherapy for breast carcinoma. Cancer 62: 467-473

Puddefoot JR, Barker S, Glover HR, Malouitre SD, Vinson GP (2002) Noncompetitive steroid inhibition of oestrogen receptor functions. Int Cancer 101: 17-22

Puddefoot JR, Udeozo UKI, Barker S, Vinson GP (2006) The role of angiotensin II in the regulation of breast cancer cell adhesion and invasion. Endcocrine Related Cancer (In press)

Quan A, Baum M (1996) Endogenous production of angiotensin II modulates rat proximal tubule transport. J Clin Iinvest 97: 2878-2882

Ronquist G, Rodriguez LA, Ruigomez A, Johansson S, Wallander MA, Fritz G, Svardsudd K (2004) Association between captopril, other antihypertensive drugs and risk of prostate cancer. Prostate 58: 50-56
Suganuma $\mathrm{T}$, Ino $\mathrm{K}$, Shibata $\mathrm{K}$, Kajiyama $\mathrm{H}$, Nagasaka T, Mizutani $\mathrm{S}$, Kikkawa F (2005) Functional expression of the angiotensin II type 1 receptor in human ovarian carcinoma cells and its blockade therapy resulting in suppression of tumor invasion, angiogenesis, and peritoneal dissemination. Clin Cancer Res 11: 2686-2694

Tahmasebi M, Puddefoot JR, Inwang ER, Goode AW, Carpenter R, Vinson GP (1998) Transcription of the prorenin gene in normal and diseased breast. Eur J Cancer 34: 1777 - 1782

Tahmasebi M, Puddefoot JR, Inwang ER, Vinson GP (1999) The tissue renin-angiotensin system in human pancreas. J Endocrinol 161: $317-322$

Uemura $\mathrm{H}$, Ishiguro $\mathrm{H}$, Nagashima $\mathrm{Y}$, Sasaki T, Nakaigawa N, Hasumi H, Kato S, Kubota Y (2005) Antiproliferative activity of angiotensin II receptor blocker through cross-talk between stromal and epithelial prostate cancer cells. Mol Cancer Ther 4: 1699-1709

Vinson GP, Ho MM, Puddefoot JR (1995) The distribution of angiotensin II type 1 receptors, and the tissue renin-angiotensin systems. Mol Med Today 1: 35-39

Vinson GP, Saridogan E, Puddefoot JR, Djahanbakhch O (1997) Tissue renin-angiotensin systems and reproduction. Hum Reprod 12: $651-662$ 